\title{
A usabilidade em estudo: experiência de compra e de leitura de quadrinhos em meio digital. Estudo de caso do aplicativo Dc Comics para iPad
}

\author{
A usability study: the experience of buying and reading comics in digital media. Case \\ Study Dc Comics App for iPad.
}

\author{
Eduardo Ariel S. Teixeira
}

experiência de uso, design de interação, usuários

\begin{abstract}
A pesquisa sobre Interação Humano-Computador, no âmbito dos estudos sobre a usabilidade da interface de produtos digitais, é focada na estrutura de interação que permite tanto a compra como a leitura de quadrinhos em um dispositivo de manipulação direta, dentro do segmento de entretenimento. Nele está sendo proposto o estudo de caso da plataforma de leitura de quadrinhos da DC Comics para o tablet Apple iPad.
\end{abstract}

user experience, interaction design, users

Research is based on Human-Computer Interaction in the context of studies on the usability of the interface digital products. It's also focus on the structure of interaction that allows both the buying and reading comics on a direct manipulation device within the entertainment segment. Therewith it is proposed case study platform for reading DC Comics for the Apple iPad tablet.

\section{Introdução}

A pesquisa sobre Interação Humano-Computador, no âmbito dos estudos sobre a usabilidade da interface de produtos digitais, é focada na estrutura de interação que permite tanto a compra como a leitura de quadrinhos em um dispositivo de manipulação direta, dentro do segmento de entretenimento. Nele está sendo proposto o estudado de caso da plataforma DC Comics para o tablet Apple iPad.

O presente trabalho relaciona-se ao desenvolvimento de sistemas e/ou interfaces projetados sob a ótica do usuário. Nele considera a abordagem ergonômica como um instrumento para minimizar as frustrações vividas pelos usuários ao utilizarem interfaces multimídias de manipulação direta. Ainda cabe destacar que a pesquisa tem uma natureza qualitativa, já que ela trata de questões relacionadas com satisfação (prazer decorrente da utilização) e não desempenho (tempo e número de cliques por tarefa).

\section{Justificativa}

Com o aumento da disponibilidade em conectividade, por conta em parte da ampliação da Internet banda larga, novos produtos surgiram no mercado. Dentre eles está o iPad, irmão mais velho do iPod Touch, sendo o primeiro tablet a alcançar um real sucesso de mercado. De acordo com o Jornal O Globo, em matéria publicada no dia 05/04/2010 às 10h37, o iPad vendeu 300 mil unidades no primeiro dia de seu lançamento nos EUA, chegando a 2 milhões de aparelhos vendidos em menos de 60 dias após o seu lançamento na Europa, Austrália, Canadá e Japão (conforme o site http://www.oglobo.com.br publicou em 31/05/2010 às 14h37. Além disso, os seus compradores baixaram mais de um milhão de aplicativos da Apple Store e 250 mil livros na iBook Store no mesmo dia.

No caso desta pesquisa, o objeto material de estudo (aplicativo DC Comics para iPad) tem como primeira função a venda de quadrinhos digitais, permitindo a sua leitura com ferramentas 
que o impresso não possui (ampliação da página, navegação não linear pelas páginas através de uma coleção, leitura por quadros ou frames, categorização da coleção e recuperação da informação seguindo critérios pré-definidos pelo usuário).

\section{Referência teórico}

Considere quantos produtos são usados no dia-a-dia. Agora se indague acerca da quantidade de produtos interativos existentes em nossa vida cotidiana. De acordo com Robinson (2004), a tecnologia moderna está avançando de modo tão veloz que a maior parte dos consumidores está ficando confusa e frustrada. Já para Preece, Rogers \& Sharp (2002), muitos produtos que requerem a interação dos usuários para a realização de suas tarefas não foram necessariamente projetados tendo o usuário em mente; foram tipicamente projetados como sistemas para realizar determinadas funções. Pode ser que funcionem de maneira eficaz, olhando-se da perspectiva da engenharia, mas geralmente os usuários do mundo real é que são sacrificados. O objetivo do design que preveja a interação ou tido como "Design de Interação" consiste em redirecionar essa preocupação, trazendo a usabilidade para dentro do processo de projetação. Essencialmente, isso significa desenvolver produtos interativos que sejam fáceis, agradáveis de utilizar e eficazes sempre na perspectiva do usuário.

Ainda para os autores, Preece, Rogers \& Sharp (2002), o Design de Interação compreende a atividade projetual que fornecem suporte às atividades das pessoas, seja no lar ou no trabalho.

Isso quer dizer que os produtos interativos devem considerar as tarefas principais dos seus usuários finais e, principalmente, a comunicação dessa audiência com os itens na tela que permitem interação e definem a experiência de navegação. Especificamente, significa criar experiências que melhorem e estendam a maneira como as pessoas trabalham, se comunicam e interagem. E para isso acontecer, Saffer (2007) considera que o design de interação está mais relacionado com o comportamento humano do que com a aparência da tela ou as funções escondidas de uma interface. Enquanto Winograd (1997), apud Preece, Rogers \& Sharp (2002), descreve o design de interação como "o projeto de espaços de comunicação e interação humana". Nesse sentido, o design de interação consiste em encontrar maneiras de fornecer suporte às pessoas e as suas atividades cotidianas através de uma interface que tenha um entendimento imediato, além de um estilo de interação quase natural e espontâneo. Sendo assim, essas definições de forma geral postulam que, em primeiro lugar, vêm os objetivos dos usuários, e, por último, a ferramenta (sistema, interface, tela, botão).

O objetivo de desenvolver produtos interativos agradáveis, divertidos, esteticamente apreciáveis está principalmente na experiência que estes produtos proporcionarão ao usuário, isto é, como ele se sentirá na interação com o sistema. Isso envolve explicar a natureza da experiência do usuário em termos subjetivos. As metas decorrentes da experiência do usuário diferem das metas de usabilidade, que são mais objetivas, no sentido de que estão preocupadas com a maneira como os usuários lidam com um produto interativo. A relação entre os dois é mostrada na figura seguinte. 
Figura 1 - Metas de usabilidade (Preece, Rogers \& Sharp - 2002).

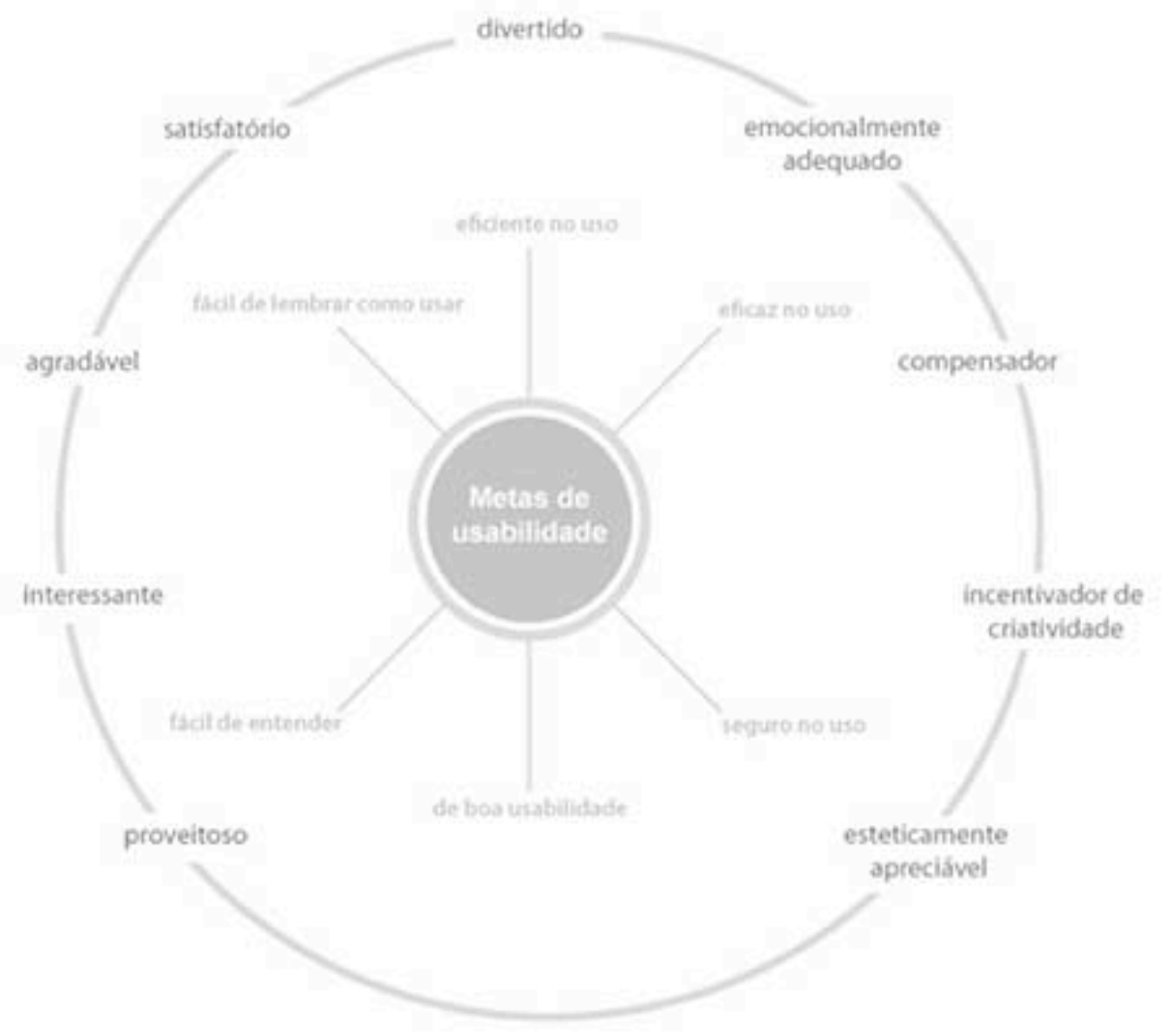

A figura mostra as metas de usabilidade e as decorrentes da experiência do usuário. As metas de usabilidade são fundamentais para uma concepção de design de interação e são operacionalizadas por meio de critérios diferentes. No círculo externo são mostradas as metas decorrentes da experiência do usuário, as quais são menos claramente definidas, porém são igualmente importantes, pois podem refletir o sentimento de prazer percebido em uma avaliação futura do produto. E elas ainda podem ter uma relação com a expectativa prévia dos usuários antes da utilização da interface.

Os sentimentos positivos decorrentes da experiência e da diversão têm sido estudados pela indústria de jogos e entretenimento, que apresenta certo interesse em entender o papel do prazer mais detalhadamente. Os aspectos descritos como contribuintes para o prazer incluem: a atenção, o ritmo, o jogo, a interatividade, o controle consciente e inconsciente, o envolvimento e o estilo da narrativa. Foi até mesmo sugerido que nesses contextos poderia ser interessante a construção de sistemas que não fossem fáceis de usar, dando oportunidades para experiências diferentes das projetadas com base nas metas de usabilidade (Frohlich \& Murphy, 1999). Entretanto, Fleming (1998) considera que a dificuldade em entender os objetivos do produto, de operar os elementos de interação e os principais comandos da interface pode transformar em uma experiência chata uma experiência que deveria ser divertida. No entanto, o uso excessivo de dicas ao longo da experiência de interação poderia tornar o uso do produto entediante, em função da banalização do desafio e da descoberta. Sendo assim, é necessário que os desafios estejam ajustados ao nível de conhecimento do usuário, pois dessa forma eles teriam o grau de complexidade correto para enriquecer a experiência e criar uma interação agradável.

E, concluindo de maneira parcial, de acordo com Preece, Rogers \& Sharp (2002), reconhecer e entender o equilíbrio entre metas de usabilidade e as decorrentes da experiência do usuário é importante. Em particular, permite aos designers conscientizarem-se das consequências de buscar combinações diferentes dessas metas, levando em consideração as necessidades dos usuários. Obviamente, nem todas as metas de usabilidade e as decorrentes da experiência do usuário se aplicam a todo o produto interativo em desenvolvimento. Algumas combinações irão também ser incompatíveis, já que pode não ser possível, ou desejável, projetar um sistema de controle de processo que seja ao mesmo tempo seguro e divertido. Portanto, o que é importante depende do contexto de uso, da tarefa a ser realizada e de quem são os usuários pretendidos. 


\section{Métodos e Técnicas}

Os métodos, técnicas e procedimentos que foram realizados na pesquisa tiveram como objetivo colher opiniões, conhecer hábitos, descobrir dados sobre a população usuária. Assim foram selecionadas as técnicas abaixo, conforme a sequência listada nesses mesmos itens:

- Questionário de "Personas".

- Cenários.

- "Teste de Usabilidade Formal".

- Questionário de "Avaliação de Prazeres".

Ainda com relação a metodologia, o questionário "Creating Personas" foi responsável por mapear o perfil do usuário médio do objeto material, fornecendo dados relevantes para a seleção do público que participará da pesquisa. Com essa técnica, ainda foi possível entender o que o personagem (o possível usuário) afetivamente necessita do produto. E, finalmente, essas informações referentes à Persona foram usadas como base para a criação dos cenários.

O teste de usabilidade possibilitou perceber as dificuldades, frustrações e comportamentos inesperados demonstrados pelos usuários no instante em que eles interagiam (se comunicavam) com o objeto material (aplicativo DC Comics para iPad). Ainda sobre a técnica, a seleção dos usuários respeitará as informações provindas do questionário de Personas, as tarefas serão apresentadas no formato de Cenários e os colaboradores responderão, após a última tarefa, o questionário de avaliação de prazeres do Jordan para quantificar o prazer que a leitura de quadrinhos em formato digital propiciou para eles durante a interação proposta.

Para Scapin e Bastien (1997), um método de avaliação baseado em critérios ergonômicos visa abranger vários aspectos da qualidade ergonômica de sistemas interativos e dentre eles está a satisfação que é um dos aspectos que se visa observar nesta pesquisa. No desta mensuração da satisfação, segundo Motta (1999), deve ser compreendida como um processo e não como um episódio de pesquisa. Ela visa transformar dados obtidos dos consumidores em dados de decisão, aliando-os com uma atitude de melhoria do desempenho. Sendo assim, essa mensuração avalia a satisfação, que é, na verdade, uma medida de sentimento, não de cognição. Muitos consumidores não sabem descrever um atributo de um serviço, mas são capazes de dizer o quanto estão satisfeitos, sendo isso o que importa.

O autor considera, ainda, que a satisfação é o sentimento do usuário quanto ao atendimento de suas necessidades e desejos. Reflete o grau de consistência entre o que o consumidor espera de um serviço e o que percebe após o consumo. Assim, o consumidor revela-se satisfeito ou insatisfeito após comparar um padrão preestabelecido por ele mesmo e sua experiência com o serviço. Ele avalia o seu nível de satisfação por sua posição inferior ou superior em relação a esse padrão, bem como pela intensidade que credita a essa posição.

\section{Resultados}

\section{Teste formal de usabilidade}

Para o teste de usabilidade foram selecionadas as tarefas abaixo:

Tabela 1: Tarefas propostas para o teste de usabilidade (Teixeira, 2011).

\begin{tabular}{|l|l|}
\hline Tarefas & Tempo previsto \\
\hline 1. Encontrar a revista Justice League $n^{\circ} 1$ desenhada pelo Jim Lee. & 60 segundos \\
\hline 2. Configurar para sempre ver toda a página antes de pular para a seguinte. & 40 segundos \\
\hline 3. Ler a revista até a última página. & 180 segundos \\
\hline 4. Avaliar a revista lida. & 85 segundos \\
\hline
\end{tabular}


Para facilitar o entendimento sobre os resultados foram escolhidas duas cores como rótulos, conforme a tabela abaixo demonstra:

- Cinza claro - representa o sentido de sucesso na realização da tarefa dentro do tempo previsto.

- Cinza escuro - representa o insucesso na realização da tarefa, seja pelo término do tempo previsto, pela solicitação de ajuda ou por desistir de realizar a atividade proposta.

Quadro 1: Realização das tarefas (Teixeira, 2011).

\begin{tabular}{|l|l|l|l|l|}
\hline Usuários & & & & \\
\hline CTA04102011 & $\mathbf{1}^{\text {a }}$ Tarefa & $\mathbf{2}^{\text {a }}$ Tarefa & $\mathbf{3}^{\text {a }}$ Tarefa & $\mathbf{4}^{\text {a }}$ Tarefa \\
\hline DMR04102011 & & & & \\
\hline FTT04102011 & & & & \\
\hline DBE04102011 & & & & \\
\hline RVAM05102011 & & & & \\
\hline
\end{tabular}

De modo geral, as verbalizações negativas quase sempre indicavam dificuldades percebidas ou recursos não encontrados no aplicativo, especialmente durante a realização das tarefas:

- “... os botões de setting's que estão na parte inferior são difíceis de serem notados; talvez uma versão branca seria mais visível, principalmente por conta do contraste".

- "... valorizo a tangibilidade da revista em si, plastificando-a após o uso e gerando uma coleção".

- “... tive alguma dificuldade para me localizar em alguns momentos. Uma busca seria interessante".

- “... os thumb's das páginas deveriam ser maiores”.

- “... a ordem alfabética facilita, mas podem haver outras ordenações como por exemplo cronológica ou por tema". 
Figura 2: Imagem do aplicativo com os botões.

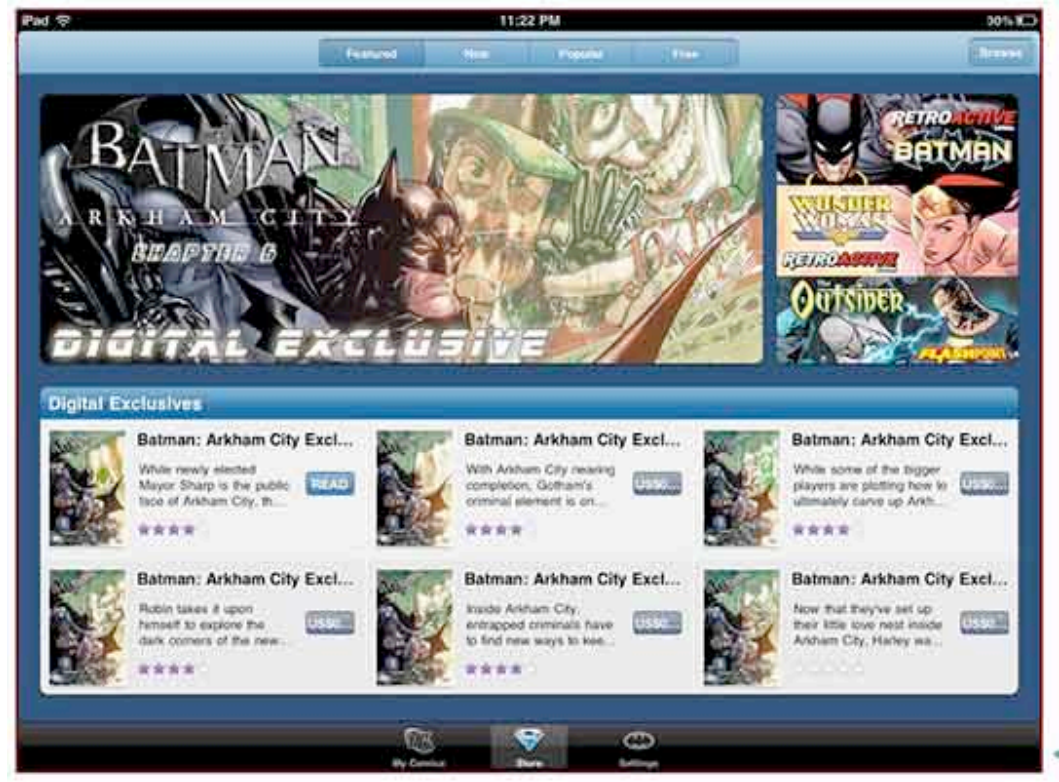

Figura 3: Imagem do aplicativo com os "thumb's".

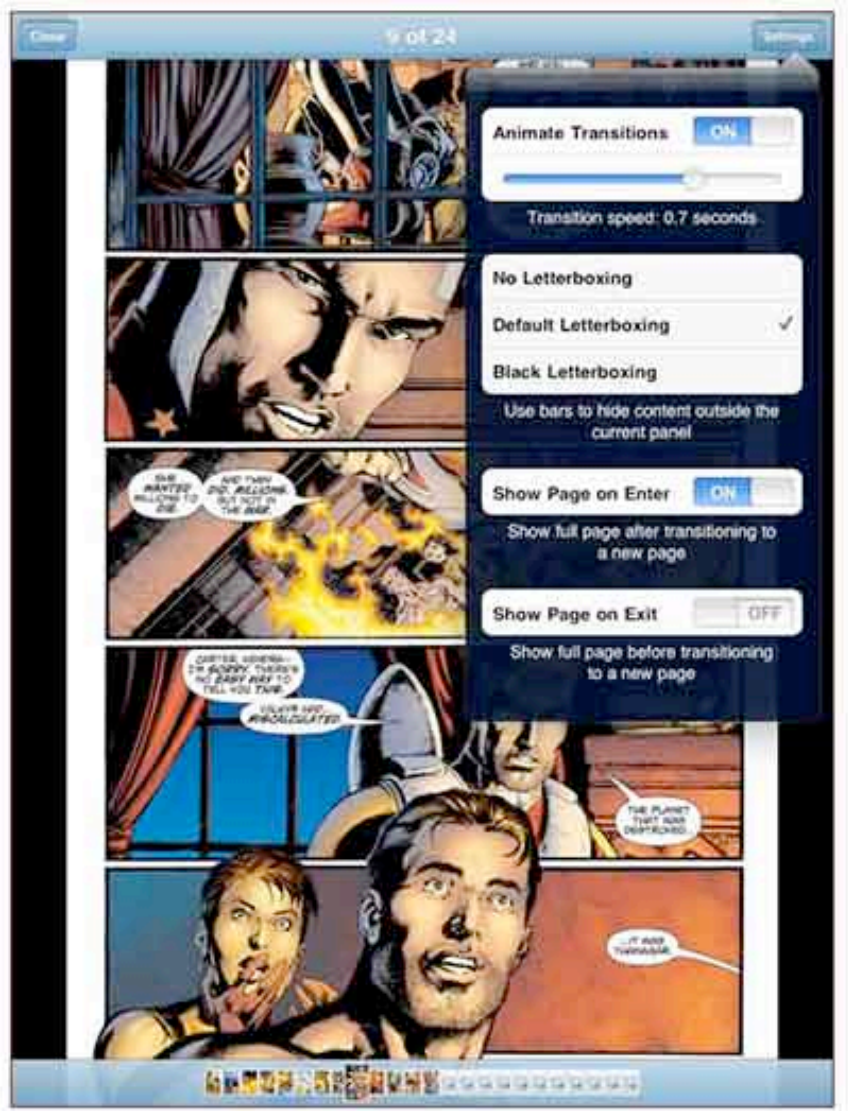

Após destacar as listas de pontos positivos e negativos pode-se, de modo mais estruturado, enfatizar e contextualizar os problemas observados. Assim, iniciando pelos aspectos que geraram satisfação, a primeira preocupação dos usuários era com relação a qualidade das imagens das revistas (resolução, tamanho, nitidez e brilho das cores) e o conforto de leitura em meio digital. Tão logo este momento tenha passado e a surpresa se torne um aspecto positivo, em especial pela possibilidade de ampliar os quadros da página - o que permitiu ter acesso aos detalhes dos 
desenhos. De modo semelhante o aumento do corpo dos textos nos balões (recurso de zoom acionado com os dedos indicador e polegar) foi essencial para garantir o conforto durante a leitura.

Já os problemas se iniciaram logo na abertura do aplicativo (na tela de apresentação dos itens da loja virtual), onde o tamanho e o contraste dos botões em relação a quantidade de itens na tela foi um fator que dificultou tanto a seleção de um produto (revista) como gerou desorientação para os usuários. Além disso, de modo global, a busca não possuía o destaque devido. Ainda sobre ela, o caso ficou mais grave no momento do acesso as coleções (seja da loja virtual ou das revistas já compradas no item "My Comic's"), a falta de critérios mais objetivos para que o usuário possa organizar a sua coleção de modo livre - assim como o seu modelo mental (conceitual/ ideal do público-alvo) indicaria.

De modo abrangente, outros itens foram responsáveis por prejudicar a interação, bem como a experiência de uso. Dentre eles estão: a falta de controles mais amigáveis durante a leitura da revista, a ausência de ajuda e de documentação com dicas sobre as formas de leitura, de organização e de busca dos quadrinhos.

Por fim, concluindo de modo parcial as observações, a avaliação da interação, em especial dos problemas já citados, também pode ser estudada dividindo os problemas em globais e locais. Para tanto, cabe antes de exemplificá-los entender uma característica presente em todos os testes com os usuários (em especial durante as verbalizações feitas por eles na execução das tarefas propostas). A comparação com o objeto índice (as revistas em quadrinho em papel), em especial quando o aspecto tangível do produto indica como os consumidores escolhem para compra, guardam seus exemplares, manipulam as suas revistas e valorizam o produto impresso. Ainda assim, tudo isso colabora para explicar o sentido de posse e, sobretudo, de coleção. Dito isso, um dos maiores problemas globais que afetaram toda a interação foi a ausência de uma explicação clara sobre os objetivos, as vantagens e as possibilidades de se ter as revistas (comic's) em meio eletrônico. Em seguida a falta de ajuda e documentação contextualizadas. Por último, a ausência de flexibilidade em organizar as revistas em critérios mais pessoais, além daqueles oferecidos pelo software (p.ex.: arcos de histórias, séries, listas e "thumbnails" ou selos). Mesmo que elas existam, o que é verdade, elas somente são exibidas no modo de "listas" através de: títulos, artistas, gêneros e editoras. No caso, o último rótulo faz referência as editoras, embora ele não funcione para esta plataforma, já que só existe uma editora (a própria DC Comics's). Assim esse botão não tem sentido e fica como uma pegadinha para os usuários. Com isso, ele poderia ser retiro da tela, diminuindo a sensação de desconforto e de dúvida.

Os problemas locais já foram descritos ao longo deste capítulo, dentro dos problemas globais, mas como o aplicativo em estudo tem uma função dedicada (compra e leitura de quadrinhos) e o seu tamanho em níveis (estrutura e extensão) de navegação é pequeno fica complicado desmembrar os casos mais particulares. Sendo assim, respeitando caráter seqüencial da interação, as não conformidades serão sempre observadas pelos impactos mais amplos (conforme visto no parágrafo anterior). Também pelas mesmas razões os problemas tiveram uma classificação em níveis de gravidade (de 1 até 4), seguindo a mesma lógica de priorizar as questões globais que afetaram a interação das pessoas durante a realização das tarefas, seja por extensão e gravidade. Assim aqueles de "nível 1" impedem a conclusão da tarefa sendo os mais graves , os de "nível 2" geram demora e frustração, aqueles de "nível 3" tem efeito menor sobre a usabilidade e, finalmente, de "nível 4" são mais sutis de cunho incremental com baixa prioridade de correção. Após todo o exposto segue abaixo a pontuação de gravidade:

- Entendimento sobre a proposta do aplicativo - "Nível 4".

- Desorientação sentida na busca pelas revistas - "Nível 4".

- Identificação de botões de acesso, de configuração e de controles de leitura têm a gravidade - "Nível 3".

- Ajuda e documentação antes e durante a interação - "Nível 3".

- Visualização dos selos ou de thumb's das páginas e das revistas têm gravidade - "Nível 2".

- Critérios e opções de organização da coleção - "Nível 2".

Em uma última análise, utilizando as informações da tabela 3 - aquela que traz os registros de sucesso ou de fracasso na tentativa de concluir as tarefas propostas, reforça o sentido de que os principais problemas são de desorientação na interação do aplicativo (seja por falta de entendimento dos rótulos ou pela densidade excessiva de elementos nos "grids" das loja virtual e 
da coleção do usuário) e não de leitura das revistas. Isto ocorre, devido as opções limitadas em favor da priorização do conteúdo principal os quadrinhos em si. Também foi observado que a curiosidade de ler e de manipular (em especial de novos modos, assim como o recurso de ampliar as imagens na leitura por "frame" permitiu) motivou os participantes do estudo, fazendo com que todos se esforçassem mais nestas tarefas (números 2 e 3 ) mesmo com as dificuldades existentes, pois elas faziam referência ao "core" ou a essência da plataforma - a razão de sua criação: a experiência interativa com a revista digital.

\section{Questionário de avaliação de prazeres}

Gráfico 1: Você possui um iPad (Teixeira, 2011).

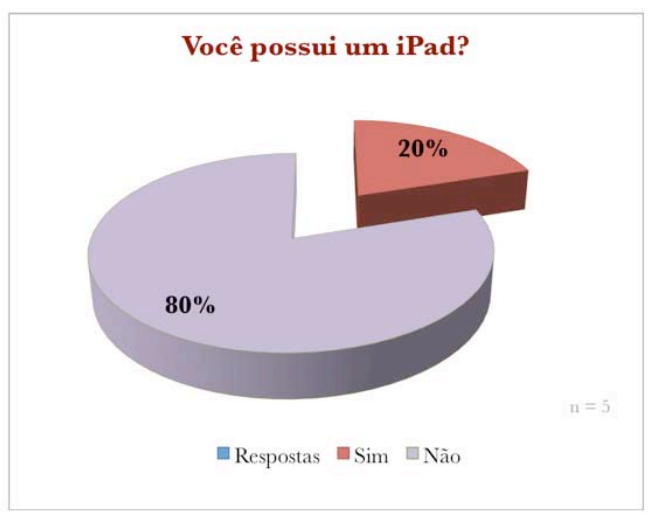

Gráfico 2: Você já leu quadrinhos em formato digital (Teixeira, 2011).

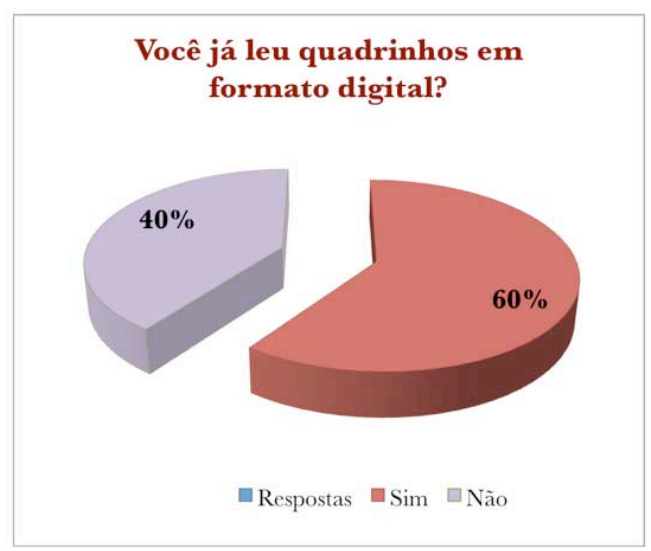

As respostas (Gráficos 1 e 2 ) indicaram que ampla maioria ( $80 \%$ dos participantes) possuíam um iPad, mas em percentual inferior $(60 \%)$ já tinham lido quadrinhos em foramto digital (Tablet, Web ou Mobile). 
Gráfico 3: Eu me sinto esimulado ao usar o produto (Teixeira, 2011).

Eu me sinto estimulado quando uso o produto.

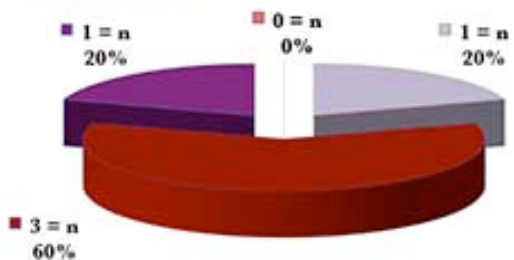

\pm 0 Discordo fortemente

घ!

Gráfico 4: Eu me divirto quando uso o produto (Teixeira, 2011).

Eu me divirto quando uso o produto.

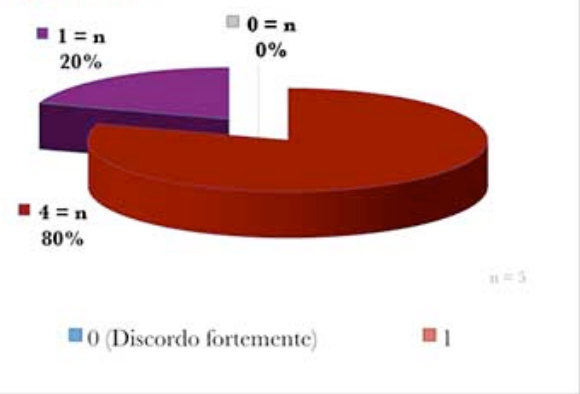

Gráfico 5: Eu me sinto atraído quando uso o produto (Teixeira, 2011).

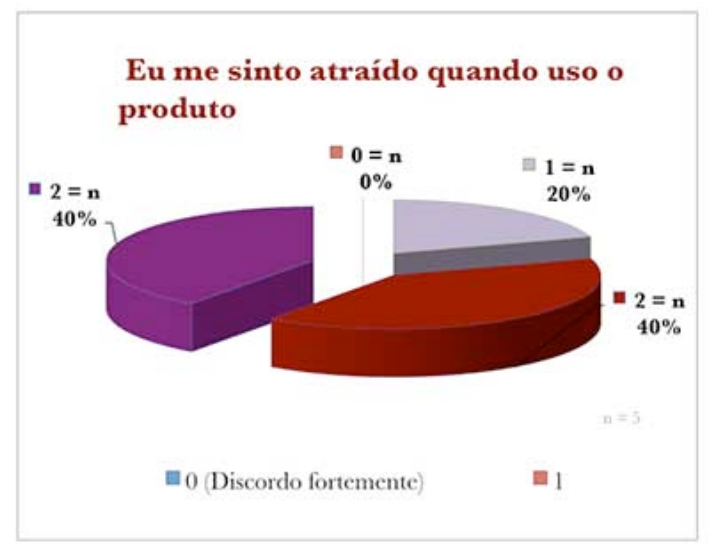

De modo similar os gráficos 3, 4 e 5 indicam com percentuais que variam de $60 \%$ até $80 \%$ para as marcações de números 3 e 4 (valores mais altos da escala) a satisfação sobre estímulo, diversão e atração para com o objeto material do estudo (aplicativo para iPad de leitura de quadrinhos da Dc Comic's). 
Gráfico 6: Eu me sinto excitado quando estou usando o produto (Teixeira, 2011).

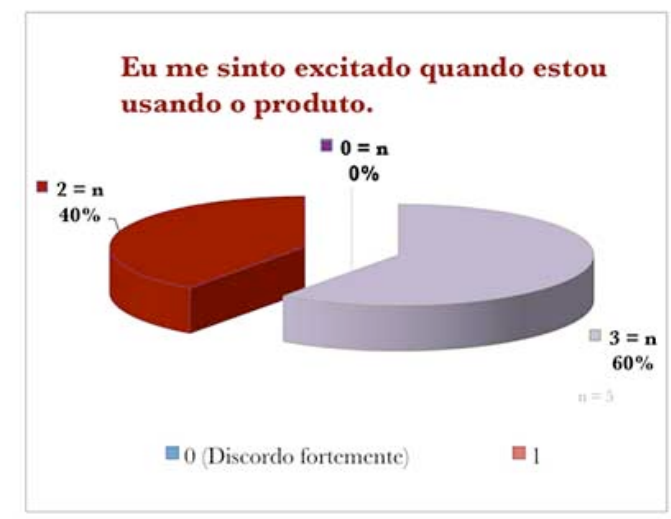

Gráfico 7: O produto me fornece satisfação (Teixeira, 2011).

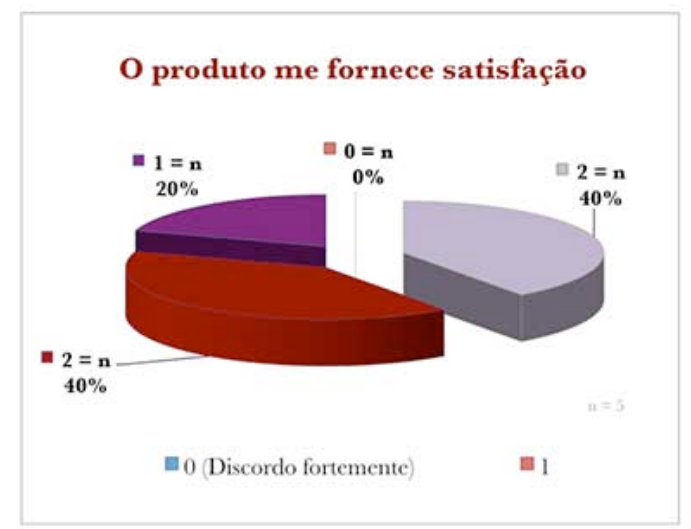

Nos gráficos 6 e 7 pode-se observar que os usuários ficaram tanto satisfeitos como excitados durante a interação com o produto. Já a satisfação teve um percentual menor $(60 \%$ para as marcações 3 e 4 da escala). No caso da excitação ela representa os aspecto com valor emocional mais forte e a satisfação traz para a equação a avaliação da experiência como um todo.

Gráfico 8: Eu posso confiar no produto (Teixeira, 2011).

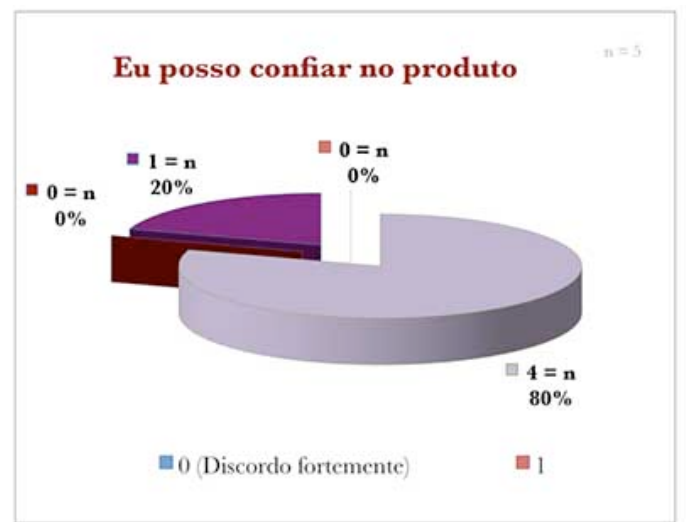

A confiança (gráfico 8) não teve uma boa avaliação, possivelmente devido a falta tangibilidade das revistas em quadrinho (preferência pelo formato impresso verbalizado durante 0 preenchimento do questionário) e das dificuldades vivenciadas pelos usuários encontraram na busca. 
Gráfico 9: Eu sentiria falta se não tivesse o produto (Teixeira, 2011).

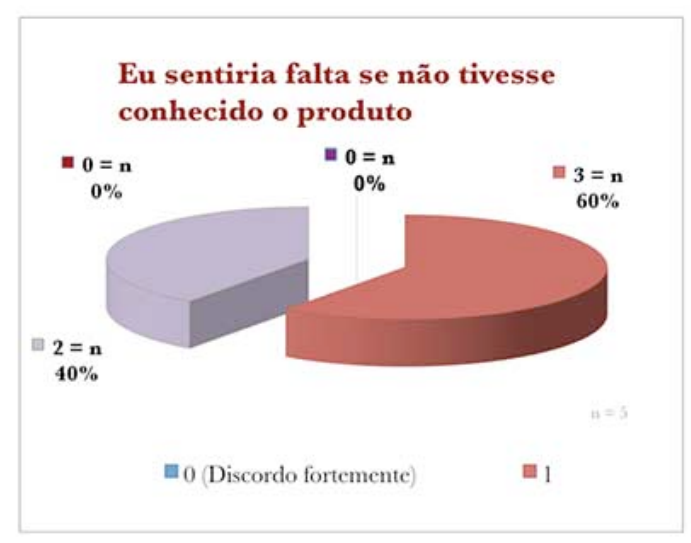

Gráfico 10: Eu tenho orgulho do produto (Teixeira, 2011).

Eu tenho orgulho do produto.

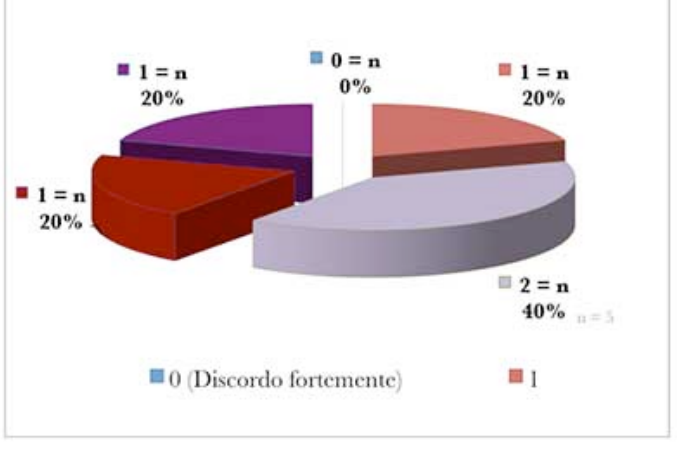

Os resultados dos gráficos 9 e 10 trazem semelhança com a observação feita para o item anterior (gráfico 8), pois ainda existe a preferência do modelo impresso e a nova proposta de leitura digital ainda gera desconforto sobre os usuários entrevistados.

Gráfico 11: Eu sinto prazer em utilizar o produto (Teixeira, 2011).

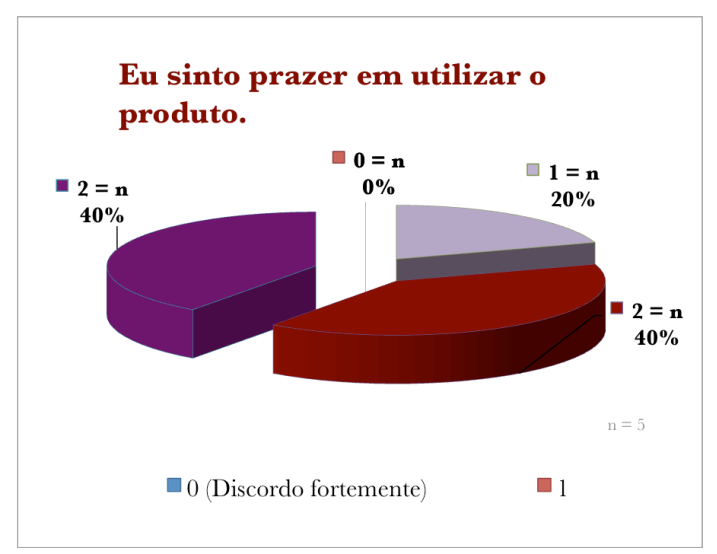


Gráfico 12: O produto me deixa entusiasmado (Teixeira, 2011).

O produto me deixa entusiasmado.

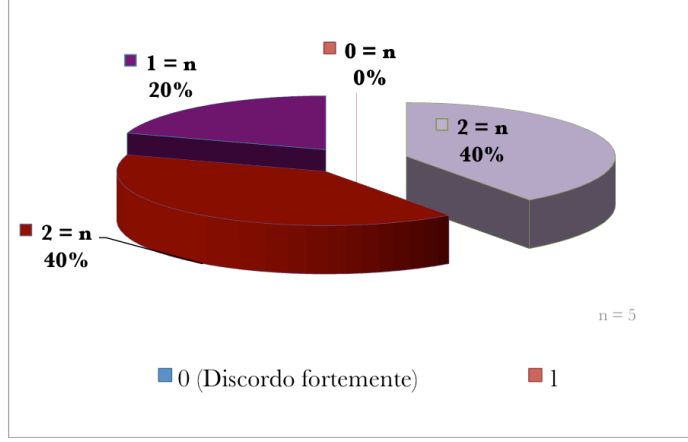

Por fim, os gráficos 11 e 12 estabelecem pelos seus resultados positivos uma perspectiva interessante para o produto em estudo, em especial sobre o prazer e o estímulo de interagir com ele.

\section{Discussão}

Neste item serão discutidos os resultados obtidos com as aplicações das técnicas em conjunto com uma breve recordação das questões chaves oriundas da revisão bibliográfica, de modo que se tenham, no seu final, os principais problemas encontrados pelos usuários durante a interação com o aplicativo da DC Comics para o ipad. Ademais, cabe enfatizar que dentre a metodologia selecionada aquela que trouxe contribuições mais diretas é o teste formal de usabilidade, pois nela se teve a interação do usuário com o produto em si. Por conta disso, pode-se estabelecer que tanto as "Personas" e os "Cenários" criados foram etapas necessárias de processo, talvez como pré-requisitos, para realização dos testes formais de usabilidade. Enquanto o questionário de "Avaliação de Prazeres" representou um instante de reflexão após a realização das tarefas, onde os colaboradores do estudo registraram as impressões de modo mais formal sobre a experiência de uso com a plataforma de leitura de quadrinhos da DC Comics para o iPad .

O referencial teórico trouxe contribuições importantes para esta pesquisa. Com ele foi possível verificar a relação entre a usabilidade, os benefícios emocionais e prazeres decorrentes de uma experiência de uso qualitativo - tudo isso contido na área de design de interação. Seguem, abaixo, algumas contribuições relevantes:

- As funções devem estar visíveis e integradas com a estética do produto, pois elas devem convidar o usuário a interagir e jamais devem ser complexas e chatas.

- O feedback aos usuários deve ser claro e em tempo hábil para que eles possam tomar decisões da forma mais confortável possível.

- A relação entre os controles disponíveis e seus efeitos deve ser evidente assim que a utilização do produto tem início.

- As metas de usabilidade devem estar equilibradas com as metas dos usuários.

O design de interação deve estimular a interação e a exploração. E essas não ocorrem por acaso, mas sim são decorrentes de um projeto de interface que leve em conta as necessidades, os desejos, a estética e as expectativas de seus usuários. No entanto, não se pode esquecer o papel das emoções como agentes que fomentam a descoberta e incentivam novas formas de interagir ou utilizar os produtos. Nesse caso, o prazer, o encantamento e a diversão são fundamentais. Nesse instante, surgiu uma questão nova que deve ter influenciado todos os usuários nos testes formais de usabilidade, a marca do produto. Com ela e, talvez por ela, mesmo com as dificuldades vividas os usuários não foram críticos com o produto (aplicativo de leitura de quadrinhos), em especial por ele estar funcionando com o iPad da Apple. Assim a marca pode também ter um papel fundamental na hora de se avaliar a usabilidade de uma interface, seja para passar confiança para aqueles que usam ou para emprestar valores ao produto (positivos geram prestígio e negativos o contrário), logo o resultado de uma equação como essa pode ser uma aura quase mítica para aqueles empresas que chegam ao patamar de "cult" - do mesmo modo que a 
Apple ocupa nos dias de hoje. Em virtude disso, as pessoas (consumidores e usuários) têm receio de falar mal do produto que possui tal tido de marca. É importante que se entenda que esta questão sobre marca e usabilidade seria um outro projeto de pesquisa, ficando como um possível desdobramento da pesquisa.

Em virtude do que já foi explicitado nos resultados do teste de usabilidade e as respostas do questionário, quando se relaciona esses resultados com a importância das emoções, é possível dizer que os sentimentos positivos podem fazer com que uma pessoa continue usando um produto mesmo que ele tenha alguns problemas de usabilidade, tal como foi sugerido no parágrafo anterior. Entretanto, a correção dos problemas de usabilidade do produto pode fazer com que ele seja melhor avaliado e estimule mais prazer em seus usuários.

\section{Referências}

BITNER, M.J. 1992. "Servicescapes: the impact of physical surroundings on customers and employees", Journal of Marketing, Vol. 56, April, pp. 57-71 (reproduced in Bateson, J., Managing Services Marketing, Dryden Press, London, 1995).

BRANDTZÆEG, P. B; FØLSTA, A. \& HEIM, J. 2004. Enjoyment: lessons from Karasek. In: BLYTHE, M. A., OVERBEEKE, K., MONK, A. F., WRIGHT, P. C. Funology: from usability to enjoyment. London: Kluwer Academic Publishers, p. 43.

CARROLL, J. M. 2003. HCI models, theories and frameworks. Toward a multidisciplinary science. San Francisco: Morgan Kaufmann Publishers Inc., Chapter 1.

CARROLL, J. M., ROSSON, M. B. 2002. Usability Engineering: Scenario - Based Development of Human Computer Interaction. San Francisco: Morgan Kaufmann Publishers Inc., 422 p.

COOPER, A. 1999. The inmates are running the asylum. Why high-tech products drive us crazy and how to restore the sanity. Indianapolis: Sams - Macmillan Computer Publishing. p. 261.

DIAS, Cláudia. 2007. Usabilidade na Web: criando portais mais acessíveis. Rio de Janeiro: Altabooks. $296 \mathrm{p}$.

DESMET, P. M. A. 2004. 'From disgust to desire: how products elicit emotions'. In: MCDONAGH, D.; HEKKERT, P.; VAN ERP, J.; GYI, D. (Org.) Design and emotion. London: Taylor \& Francis, p. 8.

DUMAS, J. S.; REDISH, J. C. 1999. A Practical Guide to Usability Testing. United Kingdom: Intellect Books, p. 22-416.

Department of the Army. (1985). Field manual (FM 101-5-1, October 21). Washington, DC: Author. DUNCAN, J., \& HUMPHREYS, G. W. (1989). Visual search and stimulus similarity. Psychological Review, 96, 433-458.

FLEMING, J. 1998. Web Navigation: Designing the User Experience. Sebastopol: Richard Koman Editor.

FROHLICH, D., MURPHY, R. (1999) Getting physical: what is fun computing in tangible form? In: Computers and Fun 2, Workshop, 20 Dec. York. UK.

GRANDJEAN, E. 1994. Ergonomics in Computerized Offices. London: Taylor \& Francis, 227p.

IIDA, I., MÜHLENBERG, P. 2006. O Bom e o Bonito em Design. In: $7^{\circ}$ Congresso Brasileiro de Pesquisa e Desenvolvimento em Design - P\&D'06, Paraná.

I.S.O. International organization for Standardization / International Electrotechanical Commission. Information Technology - Software Product evaluation - Quality characteristics and guidelines for use. - ISO/IEC 9126, Genève 1991.

JORDAN, P. W. 2000. Designing Pleasurable Products. London: Taylor \& Francis Group Books Ltd., $216 \mathrm{p}$.

JORDAN, P. 2001. An introduction to usability. London: Taylor \& Francis Group Books Ltd., 120 p.

JORDAN, P.W. 2002. How to Make Brilliant Stuff That People Love and Make Big Money Out of It. England: John Wiley \& Sons Inc., $126 \mathrm{p}$.

JORDAN, P.W. Foreword. In: BLYTHE, M. A., OVERBEEKE, K., MONK, A. F., WRIGHT, P. C. 
2004Funology: from usability to enjoyment. London: Kluwer Academic Publishers, p. 11.

KANO, N., SERAKU, N., TAKAHASHI, F., TSUJI, S. 1984. "Attractive Quality and Must-Be

Quality." Quality: The Journal of the Japanese Society for Quality Control 14 (April): 39-48.

KUNIAVSKY, M. 2003. Observing the user experience: a practitioner's guide to user research. San Francisco: Morgan Kaufmann Publishers Inc.

LÉVY, P. Cibercultura. São Paulo: Editora 34,1999: 77 - 84.

MCDONAGH, D.; HEKKERT, P.; VAN ERP, J.; GYI, D. Design and emotion. 2004. London: Taylor \& Francis, $456 \mathrm{p}$.

MOGGRIDGE, B. Designing interactions. The MIT Massachusetts: Press, 766 p., 2007.

MOTTA, P. C. 1999. Pesquisando a satisfação do consumidor. Rio de Janeiro: Imprinta Express Gráfica e Editora Ltda., 155 p.

NIELSEN, J. Ten Usability Heuristics (Nielsen, 2005). Disponível em: http://www.useit.com/papers/heuristic/heuristic_list.html. Acessado: 15/01/08.

NORMAN, D. A. 1988. The Design of everyday things. USA: Basic Books, 257p.

NORMAN, D. A. 2004. Emotional Design: Why we love (or hate) everyday things. Cambridge: Basic Books, 257 p.

NORMAN, K. L. Questionnaire for User Interaction Satisfaction - University of Maryland (Norman, 1989). Disponível em: http://www.lap.umd.edu/QUIS/index.html. Acessado: 18/07/06.

PREECE, J., ROGERS, Y. \& SHARP, H. 2002. Interaction design: beyond human-computer interaction. New York: John Wiley \& Sons, Inc., 519p.

ROBINSON, M. 'The comprehension shift, HMI of the future - designers of the future'. 2004. In: MCDONAGH, D.; HEKKERT, P.; VAN ERP, J.; GYI, D. Design and emotion. London: Taylor \& Francis, p. 18.

ROY, M.C., DEWIT, O. AND AUBERT, B.A. (2001). 'The impact of interface usability on trust in Web retailers'. Internet Research: Electronic Networking Applications and Policy, Vol. 11 No. 5, pp. 388-98.

RUSSEL, W., DARGEL, M. 2004, 22 (3), 310-320 Marketing Intelligence \& Planning.. Emerald Group Publishing Limited. From servicescape to "cyberscape". Hull University Business School, UK.

SAFFER, D. 2007. Designing for interaction: creating smart applications and clever devices. Berkeley: New Riders, 231p.

SCAPIN, D. L., BASTIEN, J. M. C. 1997. Ergonomic criteria for evaluating the ergonomic quality of interactive systems. In: Behaviour \& information technology. London, Taylor \& Francis, v.16, n 4/5, julho/ outubro. Pp 220-230.

SURI, J. F. (...) 'Design expression and human experience: evolving design practice'. In: MCDONAGH, D.; HEKKERT, P.; VAN ERP, J.; GYI, D. Design and emotion. London: Taylor \& Francis, p. 1

\section{Sobre o autor}

Eduardo Ariel de Souza Teixeira, Doutorado em Design pela PUC-Rio. Professor titular $(40 \mathrm{H})$ na ESPM-RJ e Pós-Doutorando no IBICT. Em 2012 está pesquisando a atualização do conceito de Design de Interação para profissionais da Arquitetura de Informação e Design de Interfaces. Também é coordenador da Pós em Ergodesign de Interfaces na PUC-RIO.

<eariel@espm.br; east00@terra.com.br> 